\title{
Colors in Silence - The Journey of a Synesthete in Understanding the Senses
}

\author{
Rachel Chen Siew Yoong ${ }^{\dagger}$ \\ *Nanyang Technological University \\ chenog16@e.ntu.edu.sg
}

\begin{abstract}
This paper will explore how a synesthete, RC, perceives colors, shapes, and textures in silence. RC has sound -to-color synesthesia, where at least one color is associated with each pitch on the Western music scale. Listening to silence strips all sound down to the bare minimum in terms of color or texture. As discovered through weekly meditation in a "Deep Listening" class, RC places a pitch to everything at least audible when plunged into silence, trying hard to capture the colors of every available sound. The silence also forces a more pronounced tactile sense that RC tries to grasp together with the colors. Every experience with the sound however, is present but muddled, and difficult to understand. Silence becomes an uncomfortable world of uncertainty and it becomes vital to grasp the visual and tactile nuances that are a part of it. This paper reflects $\mathrm{RC}$ 's progression through silence towards an understanding of her senses. What is silence? And how does the synesthete grapple with it?
\end{abstract}

Keywords: synesthesia, perception, crossmodality

\section{Introduction}

Synesthesia can be defined as a conscious experience of "sensory attributes that lead to involuntary experiences in a second sensory pathway" (Cytowic, 2002). An individual with synesthesia would have a specific sensory experience when encountering a different sensory experience. A common example of a synesthesic experience can include grapheme-tocolor synesthesia, where distinct colors are experienced or associated with specific graphemes.

The author of this paper, RC, came to the topic through her own personal experience with synesthesia. She has auditory-to-color synesthesia, where every pitch triggers an automatic sensation of a distinct color. RC also perceives every Western musical scale or chord as a 'set' or a 'blend' of colors. Her parents and music teacher first discovered her synesthesia at the age of 6 , when she started playing the violin. She had complained about the tuning of a certain string not being "red" enough, and was then tested for synesthesia. She also has perfect pitch.

The colors she perceived as a child have remained the same as an adult. In her later years however, she discovered that she the same pitches she hears across different instruments have varying textures, and sound that has no specific pitch is high on occurring textures, but continues to maintain some association to color.

She describes these associations as being the most clear for piano or synthesised sounds, where each note can be played percussively and concisely, and relatively less clear for other instruments or mediums such as the voice or trombone. This could be due to her early exposure to instrumental timbres. For instruments with such different timbre, the synesthete ex- 
periences the timbre as texture, which interferes with the color of it. In these cases, a tactile sensation is a more salient association with every note played. It is therefore the case that some sounds are more strongly associated with color while maintaining an association with texture, and other sounds are more associated with texture, while maintaining an association with color.

\section{A procedural overview}

The following sections begin with a description of RC's exposure to silence over a period of three months, and her personal account of the experience. These will be based on a series of journal entries over the course of 3 months. This is followed by a color chart, in which RC has selected a color to match each musical note over three octaves. Secondly, a table of texture mappings will be presented. Finally, color and texture will be compared in terms of salience.

\section{Sounds in silence}

RC underwent one semester of a 'Deep Listening' class given by Pauline Oliveros. (Oliveros, 2005 , p. 2) where she practiced weekly listening meditations, which involved listening to 10 minutes of silence. After each session, she wrote a journal entry about her experience and thoughts. Oliveros (2005), in a description of the class, states that the journal serves as a "record of progress for each individual" (p. 3).

$R C^{\prime}$ 's deep listening environments can be divided into three main categories; firstly, the music room at West Hall in Rensselaer Polytechnic Institute, secondly outdoors, and last, rooms in the Experimental Media and Performing Arts Center (EMPAC). These environments gave RC a variety of 'silent environments' to be immersed within.

The music room at West Hall can be described to be a low-noise room, and contained a consistent, quiet hum that was low in pitch. Outdoors, a wide variety of quiet sounds could be heard - slight chatter, birds singing, breeze blowing etc. In the soundproof rooms within EMPAC, there was usually almost no sound at all from the environment, so quieter sounds were easily discernible. Small sounds of distant humming could be distinctly heard on occasion.

These low-sound environments made RC question the definition of 'silence'. She writes in her journal entry $(29 / 2 / 12)$ :

"I can't hear silence. I try hard to listen to it and find it but hear everything else instead. Should I try blocking a sound out, another sound replaces it. Is silence even possible?"

In a discussion of the absence of sound, Hodkinson (2007) draws upon John Cage's composition $4^{\prime} 33^{\prime \prime}$ to illustrate silence as an object of perception. It states that in having the performers remain silent, the performance is then transposed onto audience members in "shifting perception toward other sound" (Hodkinson p. 51), a phenomenon that also occurred with RC when faced with deliberate silence.

RC found that even in extremely quiet environments, sounds were distinct and obvious, describing all sounds as 'sharp' - these quiet environments brought out the subtlest sounds. This is interesting for a synesthete because it strips sound down to its barest, bringing to attention the smallest sounds with no other distraction. These become clear or distinct enough for the synesthete to visualise.

'Silence' for RC therefore presents unusually prominent sounds that are either colorsalient or texture-salient. Sometimes however, both ring out, and these associations, although very present and real, become hard to grapple and understand: to 'catch'. Silence becomes uncertain to the synesthete since it is difficult to grasp the visual and tactile nuances of such sounds.

\section{Color-mapping}

To aid with the analysis of her silence, RC made a pitch-color chart for three octaves on synthesised piano pitches. 


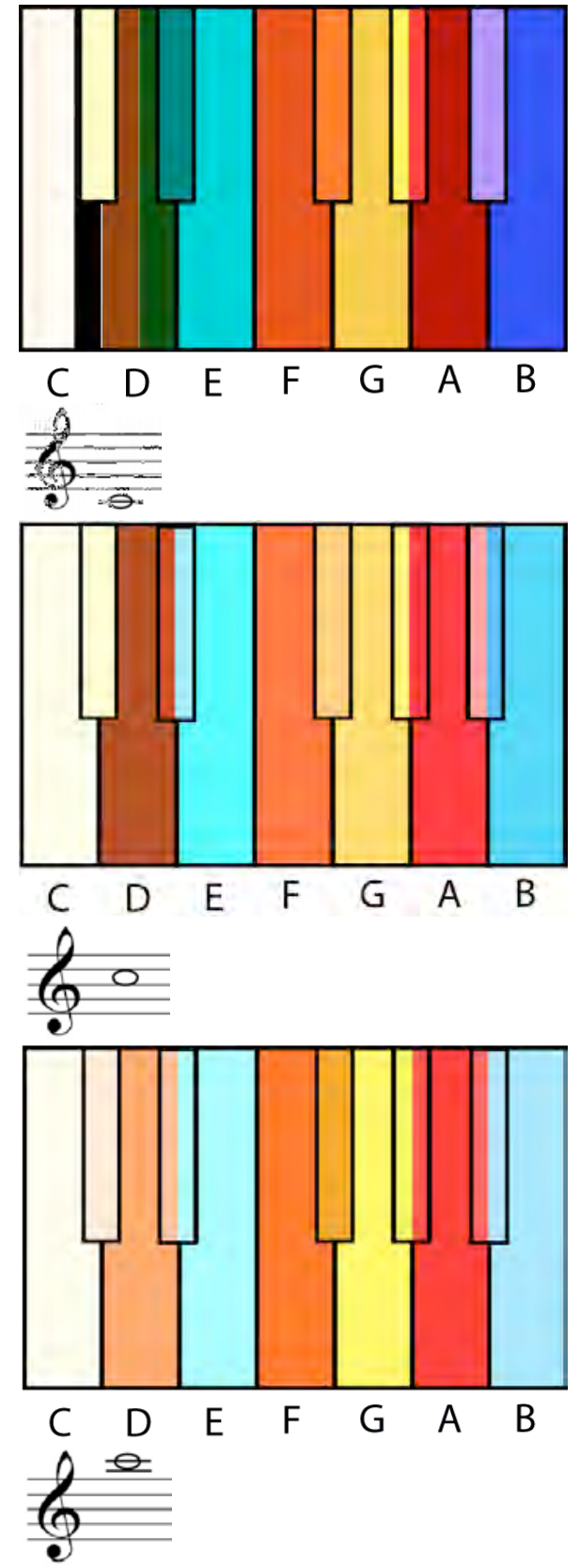

Figure 1. Pitch to color mapping for three octaves (from top to bottom in increasing pitch). Colour available in online pdf.
Some notes were found to have ambiguous colors, or to reflect two colors based on the musical context of its presentation. Pitches across octaves seem to share the same color with different shades and hues - lighter going up the pitches, and darker going down the pitches. The association of higher pitches with lighter colors, and lower pitches with darker colors is noted to be a common tendency in synesthesia literature (Cutsforth, 1925; Riggs and Karwoski, 1934; Whitchurch, 1922; Zigler, 1930; in Ward et al., 2006). Both synesthetes and non-synthetes have been found to exhibit this trend, and Figure 1 above is consistent with these findings (Ward et al., 2006, p. 268).

It is however, worth noting that RC had problems matching the appropriate colors to the relevant pitches. In her reflections she writes (11/4/12):

"I tried my best with color-matching, but the $R G B$ colors are missing a certain dimension to them. Especially as the pitches increase, it is difficult to express the lightness in color. Making red more "light" makes it look pink even though it isn't, and " $B$ " and " $E$ " seem to blend together although " $E$ " really is more turquoise."

Perhaps a next step in matching color to pitch could involve the use of paint, which would allow for the manual mixing of colors in a way that RGB colors cannot. In the meantime, these colors must be seen as portrayals, and some amount of inconsistency is inevitable.

\section{Textures in silence}

To aid with understanding her perception of texture within sounds, RC kept a record of all of the distinct sounds she heard during her weekly deep meditation, and drew textures to represent each of the sounds. A summary of the textures are presented in Figure $\mathbf{2}$ below. 


\begin{tabular}{|c|c|c|}
\hline $\begin{array}{l}\text { Projector } \\
\text { humming } 1\end{array}$ & & $\begin{array}{l}\text { This was a consistent stream of thickness with } \\
\text { small and even 'static-like' waves in the middle. }\end{array}$ \\
\hline $\begin{array}{l}\text { Projector } \\
\text { humming } 2\end{array}$ & & $\begin{array}{l}\text { This was soft and had a fuzzy quality to it. I felt } \\
\text { that I could even knead it with my hands - it felt } \\
\text { flexible in that way and open to potential change. }\end{array}$ \\
\hline $\begin{array}{l}\text { Heater } \\
\text { humming }\end{array}$ & & $\begin{array}{l}\text { This produced a consistent sound that was light } \\
\text { and thin. There were sharp spokes within the } \\
\text { texture. }\end{array}$ \\
\hline $\begin{array}{l}\text { Construction } \\
\text { work }\end{array}$ & & $\begin{array}{l}\text { This had huge chunks in them and had these lines } \\
\text { above them that crossed one another every now } \\
\text { and then, but were mostly vertical. }\end{array}$ \\
\hline $\begin{array}{l}\text { Stomach } \\
\text { grumbling }\end{array}$ & & $\begin{array}{l}\text { This came in a variety of shapes and forms, but all } \\
\text { with this sort of flow. It was a scribbly, springy } \\
\text { texture. }\end{array}$ \\
\hline Cough & & This was rough and round and small. \\
\hline $\begin{array}{l}\text { Phone } \\
\text { Vibration }\end{array}$ & andera & $\begin{array}{l}\text { This was consistent and dense and messy at the } \\
\text { same time }\end{array}$ \\
\hline $\begin{array}{l}\text { Rustling of } \\
\text { Leaves }\end{array}$ & & $\begin{array}{l}\text { There was a scrunchiness to this texture and it felt } \\
\text { malleable. }\end{array}$ \\
\hline Birds Singing & & $\begin{array}{l}\text { This was smooth and delicate, despite the } \\
\text { interruptions between the chirpping. The sound } \\
\text { quality was textured this way. }\end{array}$ \\
\hline
\end{tabular}

Figure 2. Sounds and depictions of texture. 


\section{Pitch and texture: saliency and inter- action}

Of all the distinct sounds that RC experienced, the ones that can be described to have a clear pitch were:

1. projector humming;

2. heater humming;

3. birds singing;

4. phone vibration.

These presented clear colors or a stream of colors that either interfered with, interacted with, or overwhelmed the tactile nuances of the sound.

On one occasion, the humming sound of a projector was described to have 'a mix of pitches' in it, "namely A G-B 4 and E $4-E b$, blended together in a pulse three or four times faster than my heartbeat" (Figure 3). This instance was not affected by texture, and reflects a pitch-salient sound. Although there was a distinct texture to it, the pitch was much more salient, and both texture and pitch could coexist, not affecting the other.

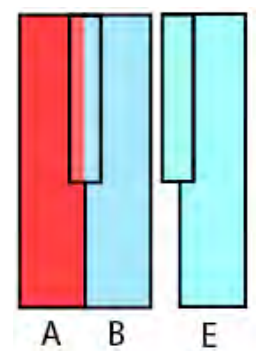

Figure 3. Projector humming (first occasion): color and texture.

However, another projector humming sound produced a different effect. As quoted from RC's accounts, "usually $B \boxminus-B b$ is $a$ deep blue, but this time because of its deep and intense humming, I identified a very dark blue, almost black." This instance is different from the previous; the texture changed the color of the sound; even though RC still heard it as the same pitch. It is thus a case of interference (Figure 4).

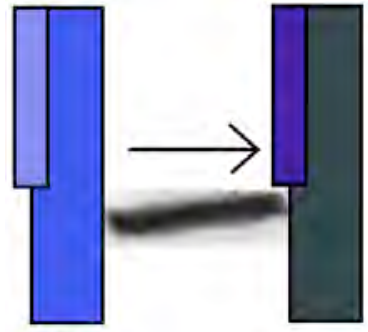

B

Figure 4. Projector humming (second occasion): color transformation by texture.

The heater humming had a high pitch; between $\mathrm{B} G$ and $\mathrm{C} \boxminus$ (Figure 5). According to previous-ly collected color mappings, this was supposed to be blue, or a shade of cream white. The texture of the heater changed the color of the sound to a shade of pinkish-red.

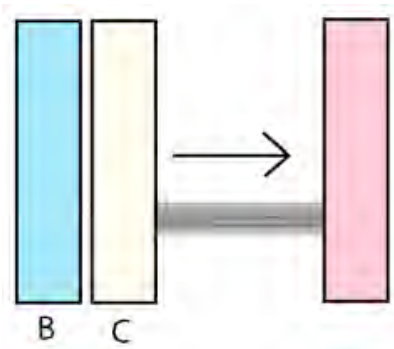

Figure 5. Heater humming: color transformation by texture.

Two other sounds presented both distinct pitches and texture: the birds' singing, and phone vibrations. The bird's singing had very dinstinct pitches in place, and they were easily dicernible because they contained light and delicate texture. Phone vibrations tended to be made up of several pitches at once, and these pitches were usually individually detectable without any effect from their texture (Figure 6).

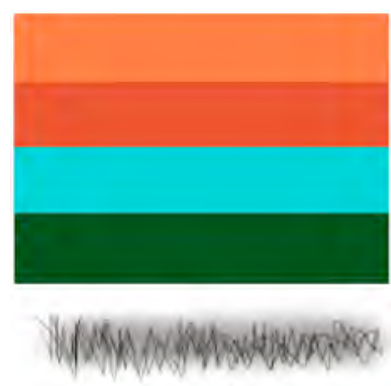

Figure 6. An example of the colors of phone vibration 
Although the textures of phone vibrations were dense, they contained some amount of 'clarity' - they were made up of discernible lines that were packed together. This stands in contrast to a dense texture, such as the first projector humming (Figure 3), where the texture was much denser and there were fewer lines since all were "melded together in a blurry mess" (journal entry: 11/4/12).

A summary of textures showcased in this section is displayed in Figure 7.

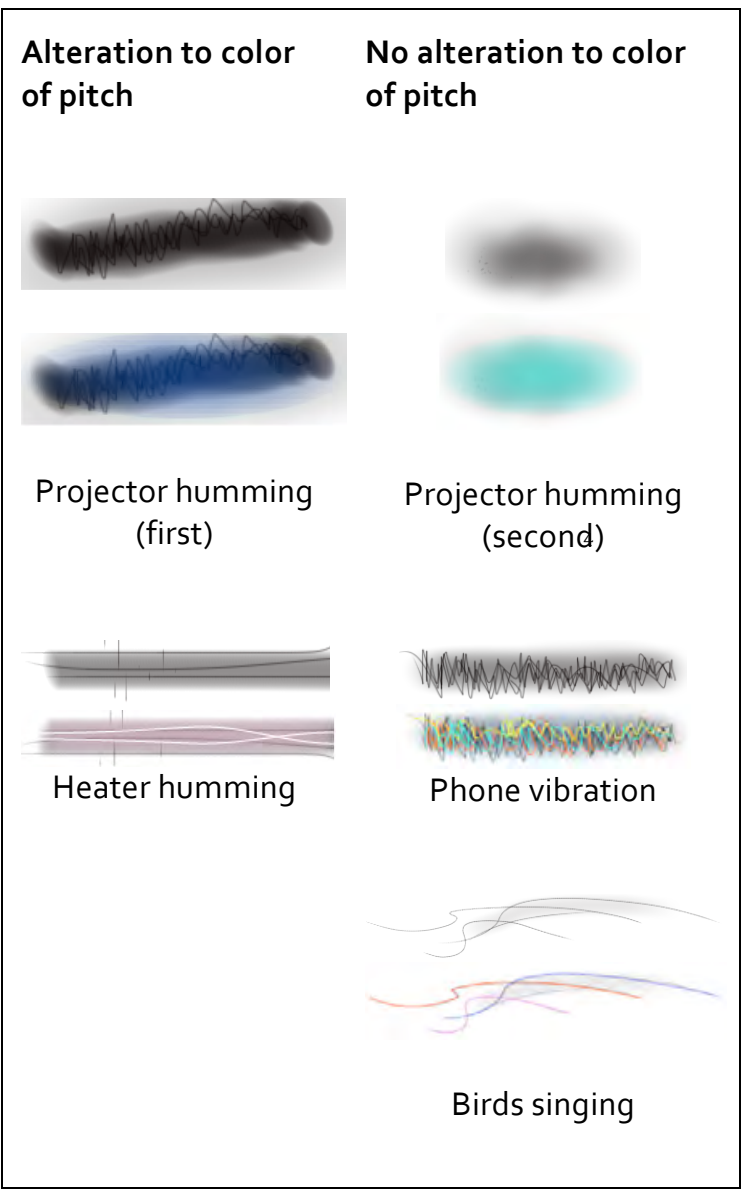

Figure 7. Effect of texture on pitch: textures from RC's journal, and artist impression for illustration purposes

In this section we took a look at the textures of sounds with clear pitch, and their interference with color associations. It is quite clear that a dense texture can cause the darkening of perceived colors, as in the case of projector humming 1. Although phone vibrations were dense as well, they had discernible, more delicate lines within the texture which allowed RC to identify matching colors to their pitches. The heater humming sound seemed to also have a dense enough texture, with fewer 'lines' that changed the pitchassociated color of the sound. The second projector humming (Figure 4) and birds singing however, did not receive any change - in the first case, the perceived colors tended to encompass the entire texture. In the latter, like the phone vibration, the individual colors were easily discernible through clear lines within the texture.

For textures that did change the perceived color of the sound, the denser the texture, the darker the color became. The lighter and sharper the texture, the lighter the color of the sound was perceived to be. This is similar to the tendency to perceive lightness with higher pitches, as discussed in Section 4.

\section{Discussion}

In this paper we have described how silence provided RC the opportunity to better understand her senses, and the ways in which she perceives sound. For a moment though, we step back for a closer look at the fundamental concept which allowed for the insight that forms the basis of the paper:

What is silence? To this question there is no straightforward answer, apart from it being a medium for a heightened awareness of sound, and in this case, RC's senses. But we do know that it is most definitely - the absence of sound, and deliberately so, in RC's case.

Returning once more to Hodkinson (2007), it is stated that "perception is influenced by intellectual understanding", and that "the sounds available for an audience to hear at a performance of (John Cage's) 4'33" will actually vary depending on their prejudices and expectations" (Hodkinson p. 51). The expectation of hearing sounds made listening to silence an impossible concept for RC, thus allowing for the vivid perception of such small sounds by RC.

Perhaps silence could take on a different meaning in an anechoic chamber, where even low-level sounds are eliminated. But for now, 
it is clear that there was no other way that RC could grapple with silence, but by being especially attentive to the few sounds left behind.

\section{References}

Cytowic, R. E. (2002). Synesthesia: A union of the senses. MIT press.

Cytowic, R. E. (2003). The man who tasted shapes. Imprint Academic.
Eagleman, D. M., \& Cytowic, R. E. (2009). Wednesday Is Indigo Blue: Discovering the Brain of Synesthesia. MIT Press.

Hodkinson, J. (2007). Presenting Absence: Constitutive Silence in Music and Sound Art Since 1950 (Doctoral dissertation, University of Copenhagen, Faculty of Humanities, Department of Musicology).

Oliveros, P. (2005). Deep listening: a composer's sound practice. IUniverse.

Ward, J., Huckstep, B., \& Tsakanikos, E. (2006). Sound-colour synaesthesia: To what extent does it use cross-modal mechanisms common to us all? Cortex, 42(2), 264-28o. 